\title{
Beyond Pitch Organization: an interview with Michael Maierhof
}

\author{
Sebastian Berweck
}

Sebastian Berweck: Michael, I always thought of your work as a composer as that of a sound researcher, as somebody who tries to get new sounds out of objects and instruments. However, I did not see you in the line of Merzbow or early Einstürzende Neubauten and was therefore quite surprised when you labeled your music as "noise music." Therefore, my first question is a very general one: what constitutes noise music in your view and where do you see yourself in this context?

Michael Maierhof: I make a distinction between pitch-organized music and non-pitch-organized music. If one does not use pitches in music as a central category, people often describe this as Geräusch-Musik, which would be the German equivalent to noise music. And because I am not writing pitchorganized music, my music belongs to the other category, which is usually called noise.

However, my strategy is to define a more elaborate concept of noise, something that I call Klangkomplexe, to describe the complex qualities of non-pitch materials.

SB: Can you explain how you make these sounds? What tools do you use and how do you find them?

MM: Because I mostly work with acoustic instruments, let us exclude the possibilities of electronics for the moment.

One possibility is to create new instruments that can produce the sound complexes I am looking for. Since 1999 I have built resonance boxes with different structured surfaces, which can be found on the backside of tiles, on 
glass, on metal gratings, and acrylic glass, for example. The performers play on these structures by using different tools to set these surfaces into vibration, for example by drawing circles with glass balls on them.

These surfaces are often structured, and when the performers draw a simple circle over the structure they can easily produce quite intricate sounds. This is a method I use, for example, in my percussion pieces Untergrund 1 for five percussion players, Untergrund 2 for four percussion players, and splitting 19.1 and splitting 24, which are for percussion solo. See, for example, splitting 19.1 (Figure 1), where the percussion player performs different figures with objects like glass marbles on a set of different metal gratings, which are separated and muted by gaffer tape. In measure 50 the right hand moves over ten different sections, each of which has a different sound. ${ }^{1}$ This single movement produces a very complex sound within the timeframe of only one beat. The sound can then be analyzed and described according to the sound characteristics of each section, their specific combination, and their density in time.

The same principle can be observed in splitting 24 (Figure 2). Here, performers move sets of glass marbles, which act as multiphonic activators, on different acrylic glass structures. ${ }^{2}$

The second possibility is to use traditional instruments-mostly pitch instruments-and redefine them through preparations, applications, and new activators.

Preparations are mostly used for transforming and/or disturbing the physical process of the instrument's vibration and thereby splitting the originally single-pitched sound into multiphonics. The model for this is, of course, John Cage's preparation of the grand piano strings with screws.

1 White regions in the diagrams above the staff indicate sections, which are separated by the gray gaffer-tape fields.

2 Indicated by gray and white regions in the figures above the staff (editor's note). 


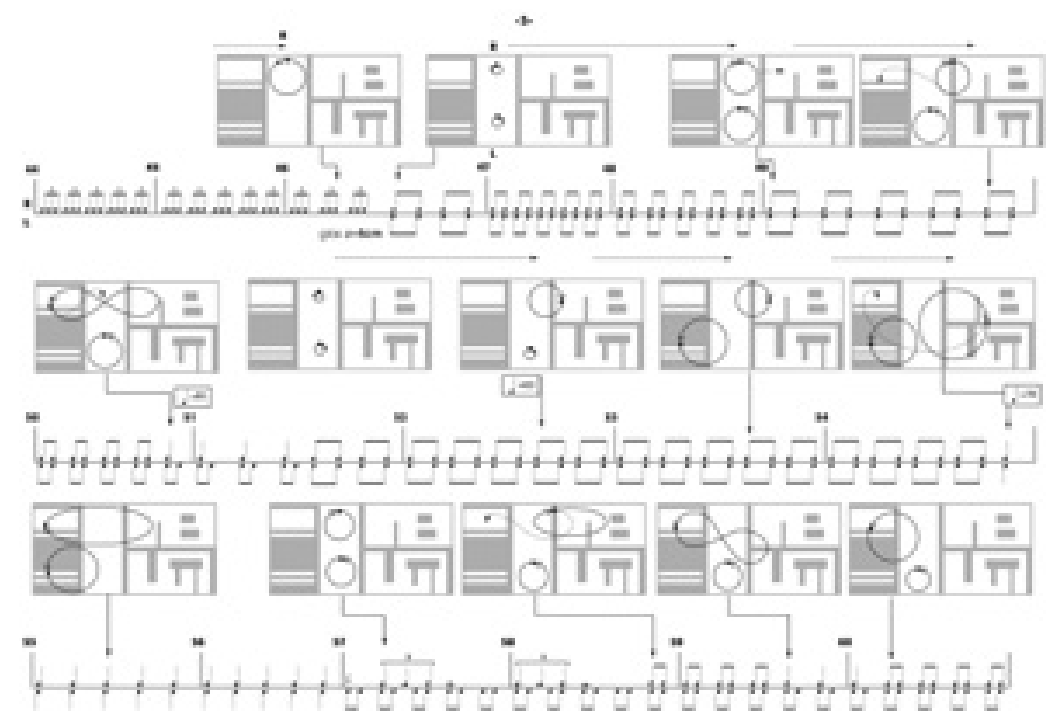

Figure 1: splitting 19.1, page 3

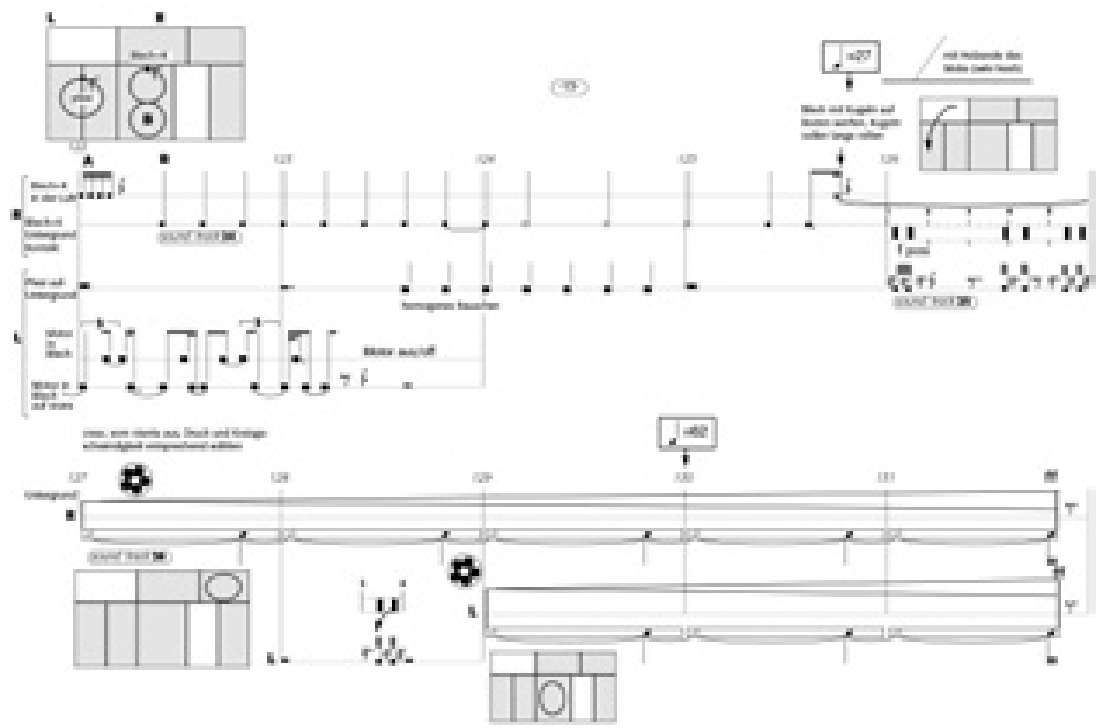

Figure 2: splitting 24, page 13 
Since the nineties I have used, for example, clothespins for the preparation of string instruments. Out of this idea-the splitting of pure pitches into sound complexes-came the rather large splitting series of pieces for solo instruments. The title arises from the fact that the originally produced pitch is used as a trigger to initiate a second physical process. Because we still connect the result of the noise or the multiphonic sounds to the original pitch as the source I find it useful to call this process pitch splitting.

Applications such as plastic cups with or without marbles produce a more complex system of vibration. They have an extra resonant space and specific vibration characteristics. They serve more as extensions of the instrument than a simple preparation.

Finally, I use something that I call new activators to initiate the physical sound process. These are not preparations as I see them. Preparations change the sound when the instrument is used in the conventional way, for example by depressing a key on a piano. However, if the piano string is not set into motion by the hammer but is being stimulated by devices such as motors we are dealing with a whole new quality.

SB: The new activators sound a bit like the ever-present cappuccino creamers that were first used in improvised music and now seem to be ubiquitous when it comes to inside-piano playing. Does this device also fall in that category?

MM: Yes, and so does the EBow and so do the sonic motors that I use. Let me explain the use of this last device in detail using splitting 36.1 as an example, which is a piano piece from 2011 and the first of four piano pieces that all explore different possibilities for defining the piano as a noise instrument. Why the piano? Because the piano is the paradigm of a pitch instrument: it is endowed with the richest possibilities of vertical and horizontal pitch combinations. And this is exactly the reason why it was the instrument composers worked with for so many centuries. 
First I use two applications, each vibration system with its own physical characteristics: a plastic cup with glass marbles placed on the middle $\mathrm{D}$ and $\mathrm{E} b$ strings and a plastic half-sphere with marbles placed on the lowest $\mathrm{C}$ and C\# strings (Figure 3, see Appendix, p.230).

The piece begins with the combination of an application and a motor: the plastic cup with marbles is set into vibration by a sonic motor. ${ }^{3}$ After two measures this sound is combined with another noise structure when the piano hammers hit the strings on which the plastic cup with the marbles has been placed. The effect of this is that the vibrating strings set the plastic cup into vibration, but the glass balls irritate this vibration and a high noisy sound emerges. This mechanical distortion is amplified by the resonant space of the plastic cup. The result of all this is a sound that contains many elements, something which in my terminology I call a sound complex. For example, the sound complex mentioned above has four different characteristics (see Figure 4):

1. a continuous sound field resulting from the sonic motor together with the plastic cup and marbles. This sound field always changes slightly because the motor constantly moves on the string. It also includes the pitched sound elements of the motor itself;

2. the sounds of the different piano strings and their respective pitches, which are activated by the slight vibrations of the sonic motor;

3. the combination of the pitches of the keys in measure 4 together with the triplet pulse and dynamic changes, which are depicted by the volume graph. ${ }^{4}$ This graph also controls the amount of noise; and

4. a sound layer that is introduced by the single impulses of the piano hammers in measure 6 and which are, in turn, distorted and amplified by the application of the plastic half-sphere.

3 A sonic motor is a motor that can be found, e.g., in ultrasonic toothbrushes; a Swiss-made model has proven to be the most musically enriching.

4 "Dynamikkurve" indicated in grey above the pitch staves (editor's note). 


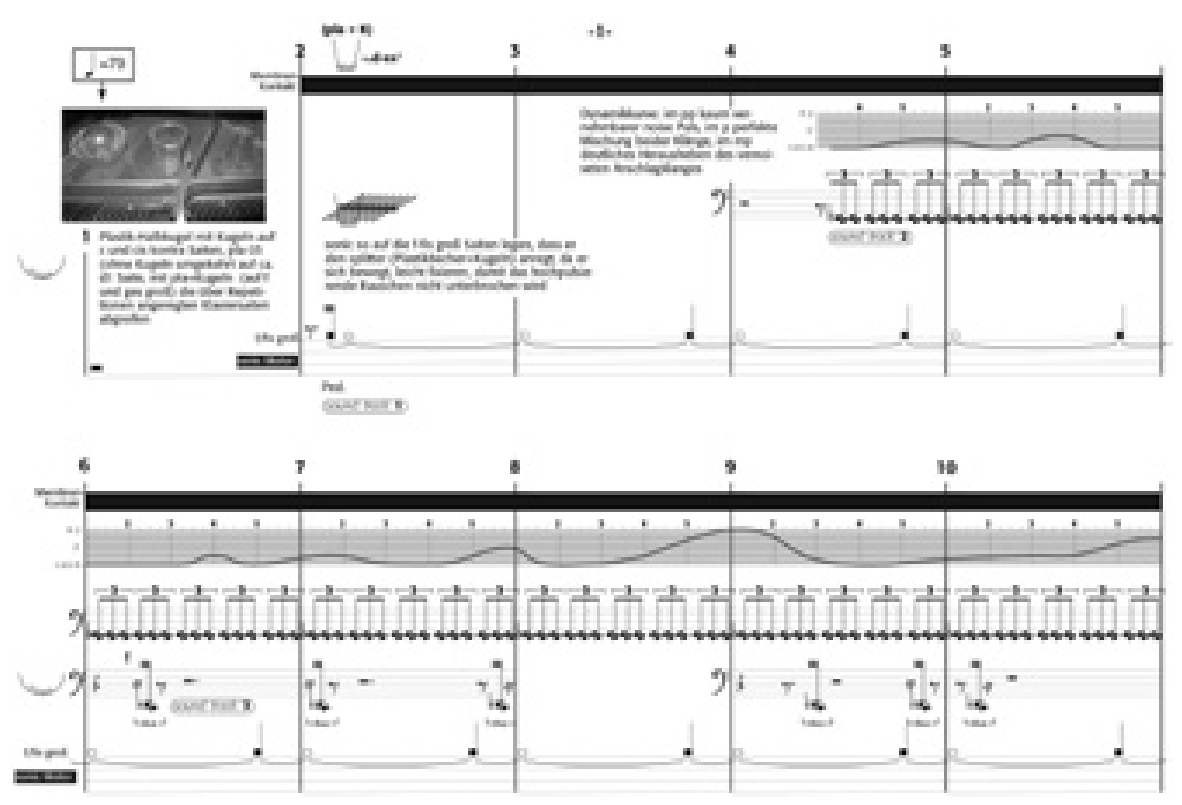

Figure 4 splitting 36.1, first page

SB: This is certainly fascinating and leaves one wondering how you find all these combinations. When you start a new piece, is there a systematic process you use in your approach to the instrument?

MM: When I explore the sounds, the fascination of the sounding material is mostly the starting point for a new piece. I make lists of possibilities, but not like a scientist who wants to explore all aspects. As early as the process of material exploration, I am already trying to work like an artist, with special focuses and interests, and always searching for the piece that will arise from this research.

Noise music or music generated with sound complexes has different production procedures to pitch-organized music. Because of the complexities in the sound itself, its construction takes place more within the sound than in pitched music, where you have known material and the composition process 
is all about the combination of the pitches, which can be planned beforehand. In non-pitch-organized music, analyzing material and formal processes through listening is probably more important than in pitched music.

From the beginning of my compositional work I was interested in exploring sounds and physical processes. Inspired by my studies of art history, it was clear to me that artists have to develop their own material, for example Renaissance painters who worked on new techniques of mixing and fixing color pigments. Personally, I was somehow not satisfied that most composers would adopt pitch material, and that their writing is then just a question of re-arranging the pitches.

SB: Does this mean that you were right from the start looking for another way to produce music? In the sense that you took a step back, looked at the production of contemporary classical music, and decided that there must be something else other than pitched music?

MM: Yes. From the beginning I wanted to produce non-pitch-organized music. It started with me preparing the cello, an instrument I studied a little bit at university, and so I could try out things at home. Suddenly a whole cosmos of sounds emerged from that extended instrument, which was propulsive and productive.

SB: So when you started to write music and you decided to write non-pitched music, did you not run into the problem of how to organize time? How do you organize time in non-pitch-organized music?

MM: More than organizing time, the problem is to organize the sounds: to create composed audible spaces that make sense, which are not arbitrary. However, this is always the point: to make music under our "everything is possible" conditions of today, to reach this point of "non-arbitrariness" [Nichtbeliebigkeit]. 
I listen to the sounds over and over again to find out what makes sense in an audible way; however, this is always connected with a few strong premises, for example that sound and silence have the same value or that sound complexes need no external relationship to be interesting in a musical sense.

SB: If I understand you correctly, you position the sounds by listening to them and finding the right place for them in a certain period of time and not by "fulfilling" a plan that you work out beforehand. Would you think that this is an approach called for by noise music, or that is even unique to noise music? Or to ask the question the other way around: is there a "traditional" composer whom you feel close to with this working method?

MM: With regard to my working method I feel closer to visual artists, some producers of electronic music, and improvisers than composers because I produce every sound I write by myself, which is normally not the working procedure of a composer.

SB: Was there a certain moment when it became clear to you that "this is it"? A eureka moment, so to speak?

MM: It has been a eureka experience over several years, actually.

SB: When we speak of noises in contemporary classical music, Helmut Lachenmann and his musique concrète instrumentale comes to mind. Here the keywords are the "emancipation of noise." In what relationship to this tradition do you see yourself?

MM: Composers in all periods have to find their position in relation to music history, society, and actual reality. My own concept of sound complexes is more an internal perspective on sounds, compared to Lachenmann's musique concrète instrumentale. My sound complexes are not a negation of anything; this is probably the most important aspect in my opposition to Lachenmann. 
His turn to pitches in the late 1980s does not mean his concept of musique concrète instrumentale has failed, but that he himself could not go on with this kind of music anymore, which I clearly can understand. However, today we have different reasons for writing or producing non-pitched music, which has more to do with our common reality. Today, to negate tradition is no longer a political act.

Let's face it: the relation between art and politics is a difficult one. For example, the claim that all good art is inherently political waters down the concept of the political so much that it becomes diffuse. I am quite skeptical when art tries to be political in a straight sense and I am not sure we can change society directly through the means of an audible event. It is already a big claim to say that art can "regenerate the perception of reality," as Gabriel Orozco says. For me, regenerating or even changing perceptions of reality is a criterion of contemporary art, and art fails easily when it tries to be explicitly political or influential.

SB: Nonetheless, people might easily think of your music as political because of the tools that you use, for example by using a cheap plastic cup on very expensive instruments like pianos and violins.

MM: I use plastic cups solely as a means to produce the sounds that interest me. As I said above, I would not dare to use the word political. I would not deny, however, that art may have a transformational energy in the long term.

Nevertheless, this is a broad field and maybe we should stick more to the subject of noise music, which sometimes is regarded as anti-pitch, or pitch as anti-noise by those who like the opposition. Still, noise can also be regarded as a pitch category, because, strictly speaking, noise is just a combination of many pitches; the strict opposition between noise and pitch makes no sense. It shows, however, that the two parts of the spectrum can be compared to black and white in the field of colors: black is the absence of color and white consists of all colors mixed together in the same amounts. This has 
always been a model for the acoustic understanding of noise; however, it's too narrow. What we are talking about is not just the pure, homogeneous white noise that is normally used as paradigm for noise. Noise, or more specifically sound complexes, can have strong internal structures, and they can be the working field of a composer.

SB: Michael, you produce every sound you write yourself and you are probably the best player of those sounds as well. For example, in a recent concert by stock $11^{5}$ at the Acht Brücken Festival in Cologne, a new piece of yours was premiered: specific objects, $11 \mathrm{~min}$. for four snare drums. Because the techniques you use are so unique-in this case the snare drums are played with sonic motors-it did not matter too much that not all the players were percussionists, as they could not fall back on learned techniques anyway. In fact, I was one of the players myself and I am a very bad drummer. Two questions sprang to mind: as you play your instruments best, why do you rely on other performers to play your music? And the second question: are those performers, who might for example be seasoned percussionists but who now have to learn a completely new and also very delicate instrument, not reduced to amateurs?

MM: Although I can play the sounds I cannot play them well enough to perform them. My music needs professional performers who know how to rehearse and to perform. I am not professional in this sense. I also need to write for larger groups and not just solo pieces. Finally, I like to collaborate with interpreters and let the sounds and the music go through another transmitter, so to speak.

To your second question: musicians who are playing extended instruments they have not studied — snare drums with motors in your example-are not amateurs. Only if I had asked you to play the snare with sticks would you

5 Musicians' collective, website accessed 16 June 2013, http://www.stock11.de/ 
have been an amateur, because there are clear standards for percussion players of how to do this professionally.

With regard to the new method of sound production in my pieces, what is needed is to develop an experimental approach and seven abilities: figuring out new playing techniques, aesthetic understanding, rhythmic precision, rehearsal experience, stage presence, transfer of body control, and the ability to have the perspective of a consistent musical interpretation. This is what separates a professional from an amateur in my view.

SB: Alright, that is a very clear statement. I would like now to ask you something I often get asked after I have played a piece of yours about the freedom of the interpreter. Earlier you have mentioned interpreters as transmitters. However, you have such a concrete vision of the sounds that you not only describe how they are to be produced but you also record them, and these recordings are an integral part of the scores. Together with instructions in the score that regulate the movement of the players in the pauses, it would seem like there is no freedom for the performers and that they are rather executors of a score than musicians who interpret a score. So, why do you prefer live musicians to recordings of your pieces?

MM: First of all, I definitely prefer a live performance because if you are working with the quality of sounds then the vibrating membrane of your stereo is completely incomparable to a sound emerging from a vibrating physical body.

Second, precision in the score does not necessarily limit the freedom of interpretation. If the score is a clear reference for the interpreters of what the composer is asking them to do, then they do not have to invest time in figuring out what the composer's ideas were. This gives the interpreters more time to find their own approach. And every interpreter has to take this freedom of their own approach. I actually expect this from a professional musician and it is in no way different from traditional music where pitch, 
rhythm, and dynamics are fixed too. I would also expect them to know about the history of interpretation or stylistic fashions.

In contemporary music there is usually not enough time to work on an attitude to the musical propositions of the composer. However, the fact that there is an unconscious interpretation of contemporary music must not be underestimated, simply because the composers and their interpreters live at the same time and share lots of acoustical and aesthetic experiences. There is an immediate understanding when it comes to the execution of the score, an understanding that is already an interpretation. This becomes clear years or decades later when musicians try to find an approach to this music again, but without having these common experiences anymore.

SB: Could you describe what changes when different performers play the same work?

MM: Every performer has a different set of skills, and the differences in the combination of the seven abilities that I mentioned above mark the difference between different performers.

SB: For the last question I would like to turn away from the practicalities of performing to those of music theory: how do you envision that your music, or noise music in general, can be analyzed?

MM: As I said before, non-pitch-organized music has a different kind of material: the material is the sound itself and its internal procedures. These are already musical statements that do not necessarily need an external relationship as in pitch-organized music.

As most theories - and they form the basis of music analysis - are pitch theories, new procedures are needed for the adequate analysis of a piece of non-pitched music. 
For example, in order to notate sound complexes, composers need to write "multimedia" scores (print, audio, video, computer scores). With the aid of such a score an analysis could start from a detailed description of the sound complexes.

Describing the manufacture of the sound complexes might possibly be another analytical approach, combined with a description focusing on the various sound layers, the sound qualities, and the sound structures in order to define them within the sound. The description earlier of the sound structures in splitting 36.1 is actually an example of such an approach. To me, this is an important strategy because it enables us to speak in detail about these sounds, which would otherwise remain opaque and abstract. In other words, separation and description are fundamental.

To put it simply, the first interest should be the internal relations of the material, and from there starts the analysis of the external relations, which would be an analysis including description and evaluation of how these sound complexes are composed. By this I mean, for example, the combinations, the sequences, the layers, the time extensions, and eventually the course or the process of the material. From there one can go on to the ideas of the piece as a piece of music.

However, many of these analyses will have to be done using different approaches before it is possible to find suitable methods. Developing a theory of the music of sound complexes is only possible through practice, and I assume that we will not end up with one general theory of noise music but with a completely new model of music theory. 
NOISE IN AND AS MUSIC 


\section{Kasper Toeplitz}

\section{What is noise (music) to you? Why do you make it?}

Noise music (or noise) is exactly what, some 25 years ago, or even earlier, made me choose "contemporary" music when deciding to become a musician, or even what made me want to play music full time, to live in music. I of course was listening to all kinds of things: jazz, rock, some classical, some more "specific" things (such as the "Canterbury school," or the English free jazz around labels such as Ogun, or musicians such as Chris McGregor) ... I had this kind of all-around interest. Good enough; I liked it. But when I first heard compositions by people such as Krzysztof Penderecki, György Ligeti, Giacinto Scelsi, and a little later Karlheinz Stockhausen and Iannis Xenakis (and many others to follow: French and Romanian spectral music, Claude Eloy, Friedrich Cerha, FrançoisBernard Mâche, Luigi Nono ...), OK, that was it-freedom in music. Much more than in free jazz, if you ask me. Freedom of structure.

But then in the following years contemporary music grew very old, and what once was freedom became a sure, tried, and safe formula. I was into music, listening to other things, discovering electronics (and MaxMSP), starting to get a little fed up of classical musicians and strict and safe ways of dealing with orchestras, string quartets, and this (very bureaucratic, very passé) world.

Then into my life came Japanoise, and noise in general, and music was exciting again! The long developments (more architecture than "proper music"), the pure physicality of the sounds (and not their "function," as you have in rock, jazz, etc.), and the passion.

In a way I am a noise musician, sure. But I also am a "contemporaryclassical" composer. I don't mean that I do those two separate things, but 
that what I do you can call what you want. Maybe I am composing noise.

So, noise music to me? Freedom of invention. And why do I make it? Well, the answer is obvious.

But it is also good to add that it is one of the purest expressions of beauty, this music. Or pure ugliness, maybe, which makes it beautiful. 